\title{
INVESTIGATION OF ANTIBACTERIAL ACTIVITY OF WASTE LIGNOCELLULOSIC MATERIALS DOPED WITH SILVER
}

\author{
TEMENUZHKA HR. RADOYKOVA, ${ }^{*}$ TSVETELINA G. ANGELOVA, \\ PAUNKA S. VASSILEVA, ${ }^{* *}$ NELLY V. GEORGIEVA, ${ }^{*}$ ALBENA K. DETCHEVA, ${ }^{* *}$ KATERINA I. \\ ALEKSIEVA, ${ }^{* * *}$ IVO V. VALCHEV, ${ }^{*}$ SANCHI K. NENKOVA* and \\ DIMITAR R. MEHANDJIEV ${ }^{* *}$ \\ *University of Chemical Technology and Metallurgy, 8 Kl. Ohridski Blvd., Sofia 1756, Bulgaria \\ **:Institute of General and Inorganic Chemistry, Bulgarian Academy of Sciences, \\ Acad. Georgi Bontchev Str., Block 11, Sofia 1113, Bulgaria \\ *** Institute of Catalysis, Bulgarian Academy of Sciences, Acad. Georgi Bontchev Str., Block 11, \\ Sofia 1113, Bulgaria \\ ๔Corresponding author:Temenuzhka Radoykova,nusha_v@uctm.edu
}

Received November 5, 2018

\begin{abstract}
The antibacterial activity of samples prepared from waste lignocellulosic materials, namely wheat straw and maize stalks, doped with silver on their surface, was investigated. In order to use the various functional groups of these materials, $\mathrm{Ag}^{+}$was applied to the carrier by the adsorption method. EPR and SEM investigations demonstrated that $\mathrm{Ag}^{+}$ ions were agglomerated into clusters of elemental silver on the carrier. The samples thus produced exhibited high antibacterial activity against gram-positive Bacillus subtilis strain 3563 and gram-negative Escherichia coli K12.
\end{abstract}

Keywords: antibacterial activity, hydrolyzed lignocellulosic materials, $\mathrm{Ag}^{+}$ions

\section{INTRODUCTION}

In recent years, considering worldwide economic and environmental pollution issues, there has been increasing research interest in the valorisation of bio-sourced lignocellulosic biomass. Agro-industrial biomass comprising lignocellulosic waste is inexpensive, renewable and abundant, providing a unique natural resource for large-scale manufacture of cost-effective products. The development of new technologies in second-generation biorefineries has led to the accumulation of large amounts of lignin as a byproduct. Lignin has an aromatic macromolecule and provides plants with firmness, protection against insects and pathogens. The traditional use of lignin to produce energy must be directed towards an innovative approach focusing on renewable materials.

The utilization of waste lignocellulosic materials from bioethanol production is an important task concerning environment protection. One possibility to solve this problem is to investigate the potential to use such materials as low-cost adsorbents or catalysts. The sorption properties of lignocellulosic materials towards metal ions are discussed in many publications. ${ }^{1-7}$ In our previous investigations, it was approved that waste hydrolysis lignocellulosic materials can be used as adsorbents for $\mathrm{Cu}^{2+}, \mathrm{Mn}^{2+}$ and $\mathrm{Ag}^{+}$ ions. ${ }^{8,9}$

Nowadays, antibacterial agents based on metal ions and nanoparticles are widely used for many applications in medicine and in the food packaging industry. One of the emerging areas in the field of nanotechnology consists in the preparation of nano-sized silver based materials. Nano-sized materials present interest due to their unique applications, including solar energy conversion, photonics, catalysis, microelectronics, antimicrobial functionalities, and water treatment. ${ }^{10}$ Initially, the reduction of various complexes with $\mathrm{Ag}^{+}$ions leads to the formation of silver atoms $\left(\mathrm{Ag}^{0}\right)$, which is followed by agglomeration into oligomeric clusters. These clusters can lead to the formation of colloidal $\mathrm{Ag}$ particles. ${ }^{11}$ In our previous investigations, we reported the formation of metallic Ag clusters on 
the surface of waste hydrolyzed lignocellulosic materials after adsorption of Ag+ ions. ${ }^{9}$

The preservation method of wood with alkaline activated hydrolysis lignin, $\mathrm{Cu}_{2} \mathrm{~S}$ and maleic anhydride has been used to modify poplar wood. ${ }^{12}$ The modified wood samples exhibited antibacterial activity against Escherichia coli K12.

Considering this, the objective of the present study is to examine the antibacterial activity of modified lignocellulosic materials based on wheat straw (hHL(s)) and maize stalks (hHL(m)) containing different amounts of silver.

\section{EXPERIMENTAL}

\section{Materials and methods}

In the present study, we used hydrolyzed lignocellulosic materials obtained by the hydrothermal treatment of wheat straw (hHL(s)) and maize stalks (hHL(m)).

The samples marked as (1) hHL(s) and (2) hHL(m) were obtained by hydrothermal treatment of wheat straw and maize stalks for facilitating hydrolysis, followed by enzymatic hydrolysis with a cellulase enzyme complex combined with $\beta$-glucosidase. The hydrothermal hydrolysis of the agricultural lignocellulosic raw materials was performed in 1000 $\mathrm{mL}$ stainless steel laboratory autoclaves, rotated at a constant rate, under the following conditions: biomass/water ratio of 1:10; initial temperature of 100 ${ }^{\circ} \mathrm{C}$; max. temperature of $190{ }^{\circ} \mathrm{C}$; heating time of 60 min, time at maximum temperature - $30 \mathrm{~min}$. Enzymatic treatment conditions were as follows: temperature $-50{ }^{\circ} \mathrm{C}$, reaction time -72 hours, lignocellulosic consistency - 10\%, initial $\mathrm{pH}$ 5.5-6.0 and 5\% charge of the cellulase enzyme complex NS 22086 in combination with $0.5 \% \beta$-glucosidase NS 22118 from Novozymes AS (both referred to the mass). All the amounts and experimental conditions were according to the Novozymes Application Sheet.

The silver-modified samples ((3) hHL(s) Ag and (4) $\mathrm{hHL}(\mathrm{m}) \mathrm{Ag}$ ) were obtained by the adsorption of $\mathrm{Ag}+$ ions according to the following procedure. To $3 \mathrm{~g}$ of waste lignocellulosic materials, $300 \mathrm{~mL}$ of $\mathrm{AgNO}_{3}$, with a concentration of $100 \mathrm{mg} / \mathrm{L}$ at $\mathrm{pH} 5.5$, was added. This mixture was vigorously stirred for $24 \mathrm{~h}$ in the dark. Finally, the samples were collected by centrifugation, dried in a common drying oven at a constant temperature of $80{ }^{\circ} \mathrm{C}$ and then maintained during 8 hours at atmospheric pressure.

\section{Sample characterization}

The cellulose content in the studied lignocellulosic materials was determined according to the KurschnerHoffer cellulose method, the lignin content - according to TAPPI standard test method T $222 \mathrm{om}-11$ (Acidinsoluble lignin in wood and pulp) and ash - according to TAPPI standard T $211 \mathrm{om}-02$ (Ash in wood, pulp, paper and paperboard: combustion at $525^{\circ} \mathrm{C}$ ).

Carbon, hydrogen and nitrogen content analysis was performed using an Elemental analyzer (Eurovector EA 3000), the oxygen content of the samples was calculated by the difference between $100 \%$ and the sum of carbon, hydrogen, nitrogen, sulphur and ash.

The initial and equilibrium concentrations of $\mathrm{Ag}^{+}$ ions were determined by inductively coupled plasma optical emission spectrometry (ICP-OES) on a Prodigy7 ICP-OES spectrometer (Teledyne Leeman Labs, USA). Measurements were carried out using the Ag II wavelength $(243.781 \mathrm{~nm}$, radial viewing) under optimized operating conditions. The calibration solutions were prepared by stepwise dilution of the stock standard solution (Titrisol, Merck, Germany). The amount of $\mathrm{Ag}^{+}$ions adsorbed onto both materials at equilibrium, $\mathrm{Q}(\mathrm{mg} / \mathrm{g})$, was determined using the difference between the $\mathrm{Ag}^{+}$ions concentrations in the solutions before and after the adsorption process according to:

$\mathrm{Q}=(\mathrm{Co}-\mathrm{Ce}) * \mathrm{~V} / \mathrm{m}$

where $\mathrm{Co}$ and $\mathrm{Ce}(\mathrm{mg} / \mathrm{L})$ are the liquid phase concentrations of the metal ions in the initial and equilibrium states, respectively; $\mathrm{V}(\mathrm{L})$ is the solution volume; and $\mathrm{m}(\mathrm{g})$ is the mass of the dried adsorbents used.

The porous structure of the sorbents was investigated by low-temperature $\left(-196{ }^{\circ} \mathrm{C}\right)$ nitrogen adsorption, using a Quantachrome NOVA 1200 apparatus (Quantachrome Instruments, USA). The specific surface area was calculated on the basis of the Brunauer-Emmett-Teller (BET) equation, whereas the pore size distribution was calculated according to the Barrett-Joyner-Halenda (BJH) method. The total pore volume was estimated in accordance with the rule of Gurvich at a relative pressure of 0.95 .

Infrared spectra were recorded on a Varian 660 IR spectrometer. The spectra were collected in the midinfrared region $\left(4000-400 \mathrm{~cm}^{-1}\right)$. The samples were prepared by the standard $\mathrm{KBr}$ pellet method.

Scanning electron micrographs (SEM) were obtained on a TESCAN instrument model SEM/FIB LYRA I XMU, using back scattering electron (BSE) detectors.

The EPR spectra were recorded as a first derivative of the absorption signal on JEOL JES-FA 100 EPR spectrometer at room temperature. The spectrometer operating in X-band is equipped with a standard TE011 cylindrical resonator. The samples were placed in quartz tubes and directly measured.

The potential antibacterial activity of the obtained materials against gram-positive Bacillus subtilis strain 3563 and gram-negative Escherichia coli K12 was evaluated on the basis of the agar diffusion test. The bacterial strains used in this study were obtained from the culture collection of Bulgarian National Bank of 
Industrial Microorganisms and Cell Cultures. The cultures were grown, sub-cultured and maintained in Luria-Bertani (LB) medium and stored at $4{ }^{\circ} \mathrm{C}$. For the experiment, a single colony of each organism was inoculated into $50 \mathrm{~mL}$ LB broth and incubated overnight $(24 \mathrm{~h})$ at $30^{\circ} \mathrm{C}$ for B. subtilis 3563 and $37^{\circ} \mathrm{C}$ for $E$. coli $\mathrm{K} 12$ with shaking at $200 \mathrm{rpm}$. $100 \mu \mathrm{L}$ of bacterial suspensions with the concentration of $1 \times 106$ CFU $\mathrm{mL}^{-1}$ were seeded in agar plates with solid LB medium by the pour plate technique. After $10 \mathrm{~min}, 10$ $\mathrm{mg}$ of pressed test materials were placed on the plates. The inhibition zones were measured after incubation overnight at $30^{\circ} \mathrm{C}$ for B. subtilis 3563 and $37^{\circ} \mathrm{C}$ for $E$. coli $\mathrm{K} 12$. The formation of a clear zone (restricted bacterial growth) around the tested tablets is an indication of antibacterial activity for the obtained materials. All determinations were performed three times in duplicate sets and the average values are reported.

The bacterial growth-inhibiting effect of the tested materials was further confirmed by plating on LB agar plates and the assay was based on the reduction of viable cells after exposure to the materials. To this aim, $100 \mu \mathrm{L}$ strain suspension and $50 \mathrm{mg}$ of each material were added to flasks containing saline solution. After $24 \mathrm{~h}$ of strain cultivations in the presence of the tested materials, $100 \mu \mathrm{L}$ of the culture broth was seeded on the LB agar plates. Samples containing only bacteria were used as controls. The plates were incubated overnight at $30^{\circ} \mathrm{C}$ for B. subtilis 3563 and $37^{\circ} \mathrm{C}$ for $E$. coli $\mathrm{K} 12$, followed by counting the number of colonies on the plates. To evaluate the antibacterial effect of the investigated materials, the percentage of cell reduction was calculated as described by Rangelova et al..$^{10}$

\section{RESULTS AND DISCUSSION}

The textural parameters of $\mathrm{hHL}(\mathrm{m})$ and $\mathrm{hHL}(\mathrm{s})$ are summarized in Table 1 . The amount of adsorbed $\mathrm{Ag}+$ ions is $5.35 \mathrm{mg} / \mathrm{g}$ and $2.58 \mathrm{mg} / \mathrm{g}$ for hHL(m) and hHL(s), respectively.

The nitrogen adsorption-desorption isotherms and the pore size distribution of $\mathrm{hHL}(\mathrm{m})$ and hHL(s) are presented in Figures 1 and 2. Both isotherms belong to type IV, according to the IUPAC classification. This is confirmed by the values of the constant $\mathrm{C}$ from the BET-equation (30 for hHL(s) and 31 for for $\mathrm{hHL}(\mathrm{m})$, respectively). In case these values are greater than 2 , the isotherms fall into type IV. ${ }^{13}$ On the other hand, the hysteresis loops resemble the $\mathrm{H} 3$ type in the IUPAC classification. This hysteresis pattern can be attributed to the crystalline agglomerates that result in the mesoporous structure formed by the interparticle space that causes the formation of secondary pores. ${ }^{14}$ The porosity diagrams are of analogous appearance, which shows that both materials possess pores of similar dimensions, with maxima in the range from 3 to $40 \mathrm{~nm}$. The calculated average pore diameters are $21 \mathrm{~nm}$ for $\mathrm{hHL}(\mathrm{s})$ and $22 \mathrm{~nm}$ for $\mathrm{hHL}(\mathrm{m})$, corresponding to a mesoporous structure.

Table 1

Texture parameters of the investigated lignocellulosic materials

\begin{tabular}{lccc}
\hline Sample & $\begin{array}{c}\mathrm{S} \\
\left(\mathrm{m}^{2} \cdot \mathrm{g}^{-1}\right)\end{array}$ & $\begin{array}{c}\mathrm{V}_{\mathrm{t}} \\
\left(\mathrm{cm}^{3} \cdot \mathrm{g}^{-1}\right)\end{array}$ & $\begin{array}{c}\text { Average pore size } \\
(\mathrm{nm})\end{array}$ \\
\hline hHL $(\mathrm{m})$ & 11.0 & 0.029 & 22 \\
hHL(s) & 10.5 & 0.025 & 21 \\
\hline
\end{tabular}

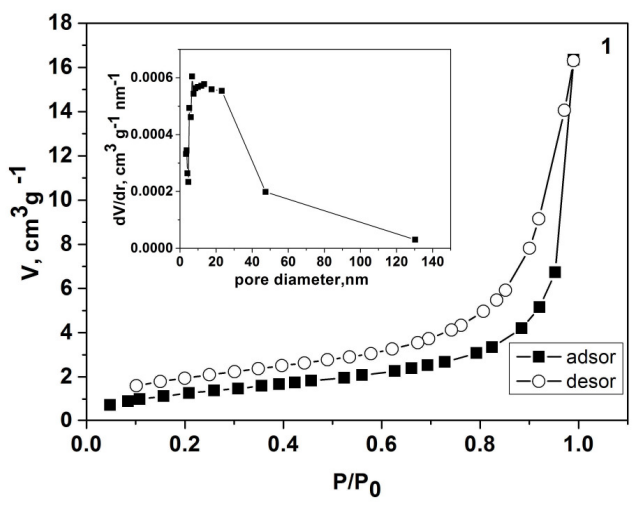

Figure 1: Nitrogen adsorption-desorption isotherms and pore size distribution of $\mathrm{hHL}(\mathrm{m})$

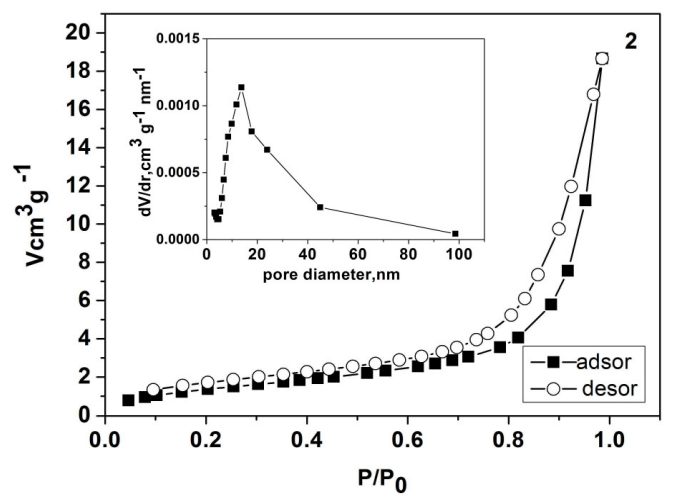

Figure 2: Nitrogen adsorption-desorption isotherms and pore size distribution of hHL(s) 
Table 2

Chemical and elemental compositions of the investigated hydrolysed materials

\begin{tabular}{llcc}
\hline \multicolumn{2}{c}{ Hydrolysed materials } & hHL(s) & hHL(m) \\
\cline { 2 - 4 } Chemical & Cellulose, \% & 50.4 & 48.6 \\
composition & Lignin, \% & 42.9 & 44.4 \\
& Mineral substances, \% & 6.5 & 6.9 \\
\hline & $\mathrm{C}, \%$ & 48.3 & 47.6 \\
\multirow{3}{*}{ Elemental } & $\mathrm{H}, \%$ & 6.2 & 5.9 \\
composition & $\mathrm{N}, \%$ & 0.6 & 0.9 \\
& $\mathrm{~S}, \%$ & - & - \\
& $\mathrm{O}, \%$ & 38.4 & 38.6 \\
\hline
\end{tabular}

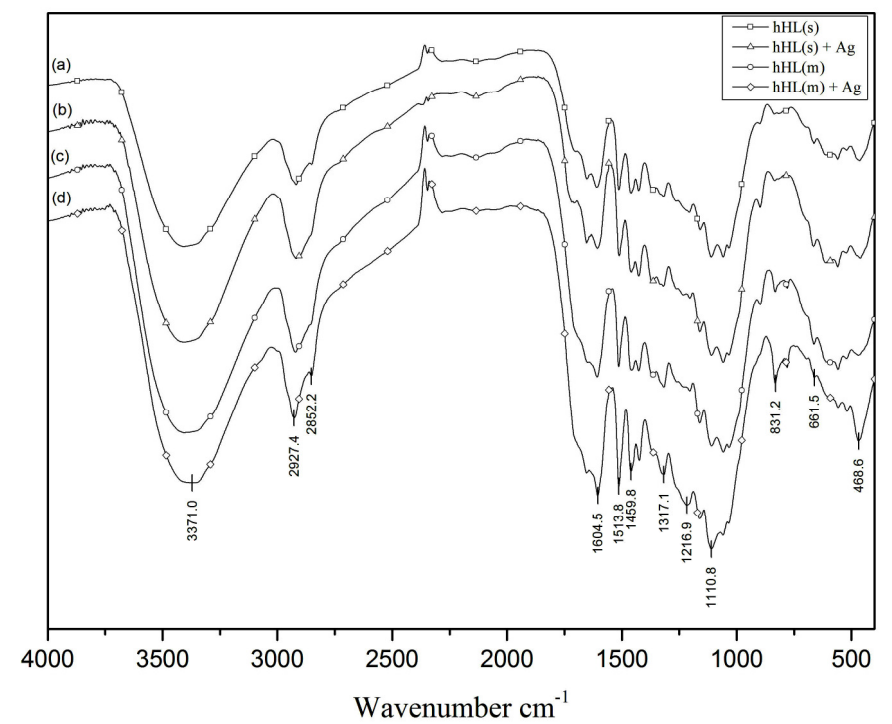

Figure 3: IR spectra of hydrolysed lignocellulosic materials before and after Ag modification

In Table 2, the data for the chemical and the elemental composition of the investigated materials are presented. The studied materials contain lignin and polysaccharides, strongly connected to the former and resistant to hydrolysis. The data indicate that the samples do not differ substantially as regards their lignin and cellulose contents, as well carbon, hydrogen and oxygen contents.

The IR spectral data of the hydrolysed lignocellulosic materials, before and after $\mathrm{Ag}$ modification, are resented in Figure 3, revealing that the spectra of the materials are similar. It is difficult to estimate the coordinate bonds between $\mathrm{Ag}^{+}$and the surface functional groups of the studied materials. It should be noted the presence of different functional groups, such as $-\mathrm{OH}$, $\mathrm{COOH},-\mathrm{C}-\mathrm{O}-\mathrm{C}-$ etc. The shapes of the spectral bands are complex and broad, due to the hydrogen bonds and the conformational structure of the materials.
The broad band in the region $3500-3100 \mathrm{~cm}^{-1}$ is due to the stretching vibrations of the alcohol and phenol hydroxyl groups, including the hydrogen bonds. The free $\mathrm{OH}$-groups show absorption at $3600 \mathrm{~cm}^{-1}$. The region of $1600-1720$ $\mathrm{cm}^{-1}$ is characteristic of carbonyl absorption. The shape and shifting of the bands did not change considerably.

There is a comparatively intensive band in the range of $3000-2850 \mathrm{~cm}^{-1}$. It refers to different types of stretching vibrations of the $\mathrm{C}-\mathrm{H}$ bonds in methyl and methylene groups. Then, two bands appear in the spectra around 1600 and $1510 \mathrm{~cm}^{-1}$, the second being usually stronger. These bands are connected to the skeleton vibrations of the aromatic rings. It is thought that the bands at 1460 $\mathrm{cm}^{-1}$, as well as at $1424 \mathrm{~cm}^{-1}$, are related to $\mathrm{CH}$ deformation vibrations in the methoxyl groups.

One of the essential questions is in what oxidative state is the surface adsorbed silver. Therefore, the EPR spectra of sample hHL(s)Ag 
(3) and sample hHL(m)Ag (4) were taken. The obtained results are presented in Figure 4.

For sample $\mathrm{hHL}(\mathrm{s}) \mathrm{Ag}$, a narrow singlet line with g-factor 2.0026 is detected by EPR spectroscopy. $\mathrm{Ag} 0$ is a paramagnetic with isotropic $\mathrm{g}$-factor, close to the free electron value of 2.0023 and therefore the narrow line above is attributed to clusters of metallic silver. EPR lines at g-factors 4.1224 and 2.1816 are due to $\mathrm{Fe}^{3+}$ ions in tetragonal and octahedral environment, respectively. The aggregation of $\mathrm{Ag} 0$ and $\mathrm{Ag}+$ ions generated additional chemically stable clusters with the general formula Agyx + , such as $\mathrm{Ag} 2+, \mathrm{Ag} 32+, \mathrm{Ag} 43+, \mathrm{Ag} 6 \mathrm{x}+$, etc. Clusters of Agyx+ type are formed in sample hHL(m)Ag and show a broad singlet line with g-factor 2.0258, besides metallic silver. The larger line width does not permit determining the hyperfine structure, as a result of which the number of $\mathrm{Ag}$ species is not clear. Silver clusters are paramagnetic, as well as $\mathrm{Ag}^{0}$ and $\mathrm{Ag}^{2+}$ species. In contrast with them, the $\mathrm{Ag}+$ ion is diamagnetic and does not exhibit an EPR spectrum. ${ }^{15}$ Therefore, the results obtained show that clusters of metallic silver are formed on the surface of the samples.

Figure 5 shows the scanning electron microscopy (SEM) image for sample hHL(m)Ag. The surface is partially covered with small bright $\mathrm{Ag}$ particles with the diameter $<0.5 \mu \mathrm{m} .{ }^{16}$

The antibacterial behavior of the tested samples (Fig. 6) was investigated against two types of microorganisms - gram-positive $B$. subtilis 3562 , and gram-negative E. coli K12. The microbiological method presents the inhibitory

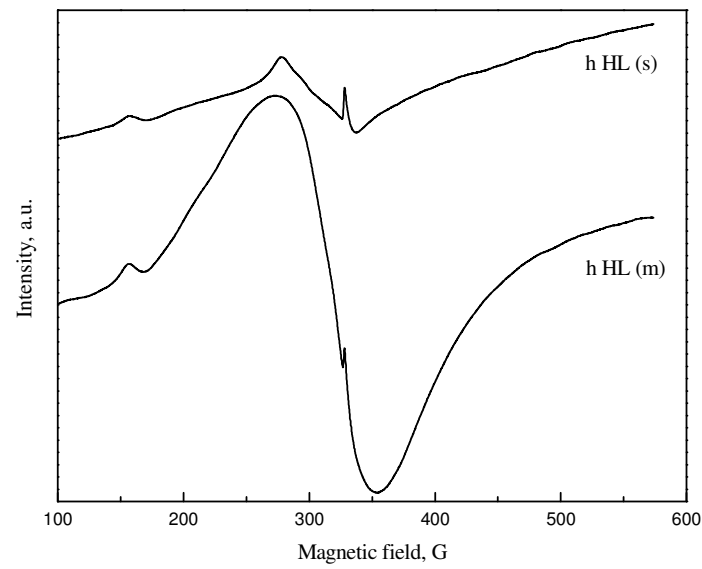

Figure 4: EPR spectra of sample hHL(s)Ag (3) and sample hHL(m)Ag (4) effect of the tested materials by measuring the inhibition zones formed around the pressed materials. No inhibition zones were detected around samples hHL(s) (1) and hHL(m) (2) for both used strains (Fig. 5). These samples possessed no antibacterial activity. The $\mathrm{Ag}^{+}$ modified hHL(m) (4) sample demonstrated bactericidal activity and formed an inhibition zone of about $12 \mathrm{~mm}$ against $B$. subtilis 3562 and of $10 \mathrm{~mm}$ against $E$. coli $\mathrm{K} 12$. The $\mathrm{Ag}^{+}$modified hHL(s) (3) sample showed less prominent bactericidal activity, namely, an inhibition zone of $2.25 \mathrm{~mm}$ against E. coli $\mathrm{K} 12$ and of $10.5 \mathrm{~mm}$ against $B$. subtilis 3562 . Moreover, gram-positive B. subtilis 3562 proved to be more sensitive against $\mathrm{Ag}^{+}$modified $\mathrm{hHL}(\mathrm{s})$ (3) and $\mathrm{Ag}^{+}$ modified hHL(m) (4) than gram-negative E. coli K12. These results can be explained by the differences in the cell walls of the two strains. The most sensitive bacteria are gram-positive, whose cell membrane contains only a peptidoglycan layer. The materials show weaker antibacterial activity against gram-negative bacteria, because of the structure of their cell membrane, which consists of a thick peptidoglycan layer and an outer lipopolysaccharide layer. This complex structure protects the bacteria from the antibacterial effect of the developed materials. ${ }^{17}$

The mechanism of action of silver ions is not fully understood. Some authors consider that ions inhibit respiratory enzymes, facilitating the generation of reactive oxygen species and damaging the cell. ${ }^{18}$

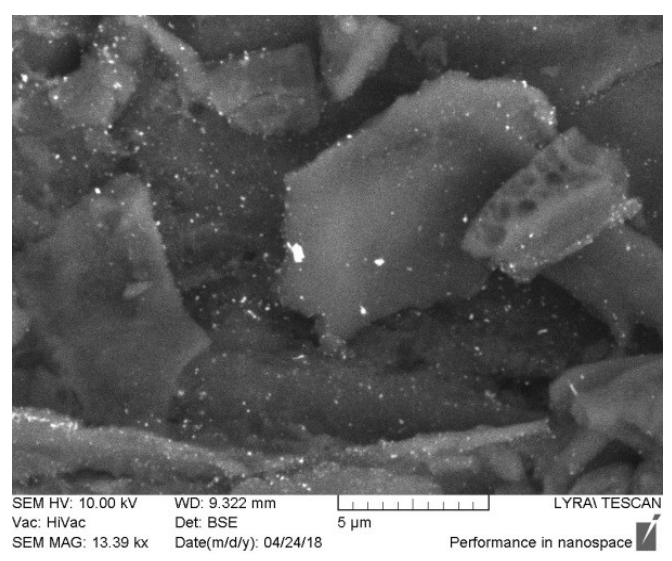

Figure 5: SEM image of sample hHL(m)Ag 

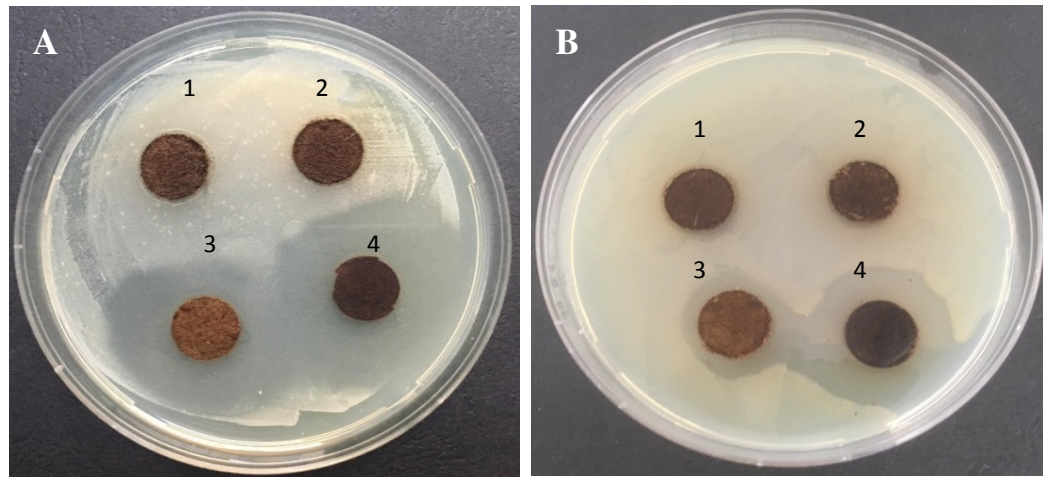

Figure 6: Antibacterial activity of (1) hHL(s), (2) hHL(m), (3) Ag+ modified hHL(s) and (4) Ag+ modified hHL(m) against B. subtilis 3562 (A) and E. coli K12 (B) after 24 hours of incubation

Table 3

Antibacterial test results for tested materials against B. subtilis strain 3562 and E. coli $\mathrm{K} 12$ after 24 hours of incubation

\begin{tabular}{ccccc}
\hline \multirow{2}{*}{ Sample } & \multicolumn{2}{c}{ B. subtilis 3562} & \multicolumn{2}{c}{ E. coli K12 } \\
\cline { 2 - 5 } & CFU/mL & $\begin{array}{c}\text { Reduction of } \\
\text { cells }(\%)\end{array}$ & CFU/mL & $\begin{array}{c}\text { Reduction of } \\
\text { cells (\%) }\end{array}$ \\
\hline Control & $5.0 \times 10^{5}$ & - & $4.8 \times 10^{5}$ & - \\
1 & $5.0 \times 10^{5}$ & - & $4.8 \times 10^{5}$ & - \\
2 & $5.0 \times 10^{5}$ & - & $4.8 \times 10^{5}$ & - \\
3 & - & 100 & $3.1 \times 10^{5}$ & 35.4 \\
4 & - & 100 & $2.5 \times 10^{5}$ & 48 \\
\hline
\end{tabular}

The growth inhibiting effect of the obtained materials was further confirmed based on the number of surviving microbial cells after cultivation in the presence of the samples. It was observed that the $\mathrm{Ag}^{+}$modified hHL(s) (3) sample and the $\mathrm{Ag}+$ modified $\mathrm{hHL}(\mathrm{m})$ (4) sample suppressed $100 \%$ growth of B. subtilis 3562 after $24 \mathrm{~h}$ of cultivation. The growth inhibition of $E$. coli $\mathrm{K} 12$ was of $35.4 \%$ by sample 3 and of $48 \%$ by sample 4 (Table 3 ). Samples hHL(s) (1) and hHL(m) (2) showed no inhibitory effect. The results confirmed that the $\mathrm{Ag}^{+}$modified $\mathrm{hHL}(\mathrm{m})$ (4) caused a stronger inhibitory effect against both strains used, compared to the other samples.

The antibacterial efficiency of lignocellulosic materials assessed using the agar diffusion test was described in an earlier study. ${ }^{12}$ In order to make a comparative, more accurate assessment, we applied Keff's efficiency factor represented by the following formula:

Keff $=\frac{d t-d o}{d o}=\frac{d t}{d o}-1$

where $\mathrm{dt}$ - the mean diameter of the tablet with the inhibition zone for time $t$; do - the diameter of the tablet. If $\operatorname{Keff}=0$, then the materials don't have any antibacterial effect.
According to the formula, the efficiency coefficient of the Ag+ modified hHL(s) sample in the presence of B. subtilis 3562 is of 1.6 , while the growth of gram-negative E. coli $\mathrm{K} 12$ is significantly less inhibited with a $\mathrm{Kf}$ of 0 . The other sample, Ag+ modified hHL(m) shows $\mathrm{Kf}=$ 2 in the presence of $B$. subtilis 3562 and $\mathrm{Kf}=1.5$ in the presence of $E$. coli $\mathrm{K} 12$. Therefore, a higher Keff is exhibited by the sample hHL(m)Ag.

\section{CONCLUSION}

Lignocellulosic waste materials produced after the enzymatic hydrolysis of plant-based raw biomass have been doped with silver and proved to have a high effect in the destruction of harmful bacteria, such as gram-positive Bacillus subtilis strain 3563 and gram-negative Escherichia coli K12 in aqueous solutions. A well-developed inner surface and active oxygen containing functional groups that adsorb silver ions lie at the core of this activity. It has been found that, in the treatment process, the silver ions agglomerate and form clusters of elemental silver, which also determine the high antibacterial activity. The comparative study of the prepared lignocellulosic materials based on wheat straw and maize stalks shows that the maize stalk samples exhibit higher 
antibacterial effectiveness. This is probably due to the higher silver content of this sample, as well as to the differences in the cell walls of the strains. The materials obtained by this method can be thus used to manufacture antibacterial products.

\section{REFERENCES}

1 K. Krishnani, X. Meng and L. Dupont, J. Environ. Sci. Health A Tox. Hazard Subst. Environ. Eng., 44, 688

(2009), https://doi.org/10.1080/10934520902847810

2 X. Guo, S. Zhang and X. Shan, J. Hazard. Mater., 151, 134 (2008), https://doi.org/10.1016/j.jhazmat.2007.05.065

3 G. Harman, R. Patrick and T. Spittler, Ind. Biotechnol., $\quad 3, \quad 366 \quad$ (2008), https://doi.org/10.1089/ind.2007.3.366

4 N. Tazrouti and M. Amrani, Bioresources, 4, 740 (2009), https://doi.org/10.15376/biores.4.2.740-755

5 C. Bumbac, E. P. Leonte, C. Dumitrescu, I. Ghita and M. Stefanescu, J. Environ. Prot. Ecol., 11, 822 (2010),

https://www.researchgate.net/publication/270742256_

Heavy_metals_removal_using_residual_fungal_bioma

J.-G. Cao, X.-M. Li, Y. Ouyang, W. Zheng and Q. Yang, J. Environ. Prot. Ecol., 12, 661 (2011), https://www.researchgate.net/publication/289319929_

Manganese_waste_water_treatment_Biosorption_of_m anganese_by_Serratia_sp

H. Bukhari, G. Shabbir, J. Rehman, M. Riaz, N. Rasool et al., J. Environ. Prot. Ecol., 14, 453 (2013), https://www.researchgate.net/publication/244990816_ Biosorption_of_PbII_CuII_and_MnII_metal_ions_fro m_aqueous_solutions_by_using_Typha_latifolia_wast e_biomass

${ }^{8}$ T. Hr. Radoykova, S. V. Dimitrova, K. I. Aleksieva, S. K. Nenkova, I. V. Valchev et al., J. Environ. Prot. Ecol., 1623 (2015), https://www.researchgate.net/publication/284981384_
Comparative_Mn2_adsorption_on_waste_lignocellulo sic_materials

9 P. S. Vassileva, T. Hr. Radoykova, A. K. Detcheva, I. A. Avramova, K. I. Aleksieva et al., Int. J. Environ. Sci. Technol., 13, $1319 \quad$ (2016), https://doi.org/10.1007/s13762-016-0970-y

10 N. Rangelova, L. Alexandrov, Ts. Angelova, N. Georgieva and R. Müller, Carbohyd. Polym., 101, 1166 (2014), https://doi.org/10.1016/j.carbpol.2013.10.041

11 S. Kapoor, D. Lawless, P. Kennepohl, D. Meisel and N. Serpone, Langmuir, 10, 3018 (1994), https://doi.org/10.1021/la00021a026

12 T. Radoykova, S. Nenkova, N. Georgieva, D. Todorova and T. Angelova, in Procs. Vienna GREEN Conference Proceedings, 27-29 November, 2017, Vol. 17, Issue 63, pp. 579-586, https://doi.org/10.5593/sgem2017H/63/S26.073

13 S. Greg and K. Sing, "Adsorption, Surface Area and Porosity", Academic Press Inc., London, 1982, https://doi.org/10.1002/bbpc.19820861019

14 P. S. Vassileva, A. K. Detcheva, T. Hr. Radoykova, I. A. Avramova, K. I. Aleksieva et al., Cellulose Chem. Technol., $\quad 52, \quad 633 \quad$ (2018), http://www.cellulosechemtechnol.ro/pdf/CCT78(2018)/p.633-643.pdf

15 E. N. Culea, P. Pascuta, M. Pustan, D. R. TamasGavrea, L. Pop et al., J. Non Cryst. Solids, 408, 18 (2015), https://doi.org/10.1016/j.jnoncrysol.2014.10.002

16 M. Yurtsever and A. Sengil, Trans. Nonferrous Met. Soc. China, 22, $2846 \quad$ (2012), https://doi.org/10.1016/S1003-6326(11)61541-0

17 Ts. Angelova, N. Rangelova, R. Yuriev, N. Georgieva and R. Müller, Mater. Sci. Eng. C, 32, 1241 (2012), https://doi.org/10.1016/j.msec.2012.03.015

18 S. Pal, Y. K. Tak and J. M. Song, Appl. Environ. Microbiol., $\quad 73, \quad 1712 \quad$ (2007), https://doi.org/10.1128/AEM.02218-06 